\section{Acute rabies death mediated by antibody}

\section{Bellur S. Prabhakar* \& Neal Nathanson}

Department of Microbiology, University of Pennsylvania Medical School, Philadelphia, Pennsylvania 19104, USA

Among inadequately immunized laboratory animals dying of rabies, a small but consistent proportion succumb after an incubation period shorter than that of any of the unvaccinated controls ${ }^{1-3.7}$ and this phenomenon has been termed 'early death'. It has also been shown that, after immunosuppression either with cyclophosphamide or by thymectomy and irradiation ${ }^{4}$, rabies-infected animals survive longer with decreased incidence of paralysis. It appears that 'early death' also occurs in humans who have been treated (unsuccessfully) with vaccine, with or without accompanying serum therapy ${ }^{5-7}$, after exposure to rabies. Collectively, these studies suggest that there is a immunopathological component in rabies virus infection. We have therefore investigated a model of lethal rabies infection in immunosuppressed mice and have concluded that B lymphocytes or antibody specific for rabies play a part in the causation of early death. Accordingly the immune response to rabies has a dual role $^{8}$, sometimes favouring survival but sometimes enhancing the disease.

In this study, we used the high-egg-passage Flury (HEP) strain of rabies virus, which causes a limited inapparent infection of the central nervous system (CNS) in adult mice ${ }^{9}$ that can be converted into a fatal infection by immunosuppression ${ }^{10}$. This fatal infection can in time be aborted by adoptive transfer of syngeneic immune spleen cells ${ }^{11}$. Adult BALB/c mice were lethally irradiated by total body irradiation (TBI) from a ${ }^{137} \mathrm{Ce}$ source $(800-850 \mathrm{rad})$. TBI and normal mice were infected intracerebrally (IC) on the day of irradiation with 5,000 suckling mouse ICLD $_{50}$ of HEP virus. As shown in Table 1, untreated TBI mice died due to radiation; but could be protected by normal bone marrow cells devoid of mature $T$ lymphocytes. Normal mice infected with HEP virus survived, but HEPinfected TBI mice died despite immunological reconstitution with bone marrow cells, clearly separating rabies death from that due to radiation.

HEP-infected TBI mice reconstituted with normal spleen cells or cells from donors immunized 30 days earlier (memory cells), died after a mean survival time (MST) of 9 days, but spleen cells from donors immunized 7 days earlier (primary immune cells) conferred complete protection with animals showing no apparent symptoms of the disease.

However, adoptive transfer of spleen cells obtained from donors 3 days after secondary immunization (secondary immune cells) resulted in early death of $28 \%$ of the recipients, while the rest survived. The animals that died within 2-3 days after cell transfer did not show any signs of paralysis, typical of rabies, but rather acute symptoms such as convulsions and tonic spasms. Onset of these symptoms was noted only a few hours before death. Histopathological examination of parasaggital sections of the brain from nine of these animals that were either moribund or just dead showed no inflammation, neuronal destruction or other alteration. By contrast, in brains obtained immediately after death from a group of eight mice dying of rabies 13-15 days after infection, foci of nectoric hippocampal cells with minimal inflammation were consistently seen.

To characterize further the immunological requirements for early death, secondary immune spleen cells from syngeneic donors were separated into $\mathrm{B}$ - and $\mathrm{T}$-cell enriched populations by passage through a nylon wool column ${ }^{12}$ or by treatment with anti- $\theta$ antibody and complement. TBI mice infected with HEP

* Present address: Laboratory of Oral Medicine, NIDR, National Institutes of Heaith, Buildin 30, Room 121, Bethesda, Maryland 20205, USA.
Table 1 Effect of TBI and adoptive cell transfer on HEP virus infections

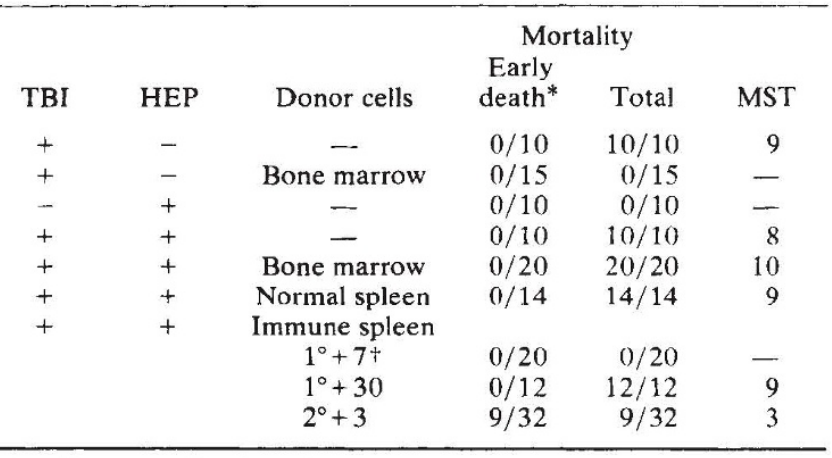

10-12-week old BALB/c mice were irradiated (800-850 rad, TBI) and on the same day were inoculated with 5,000 suckling mouse ICLD 50 of HEP virus. Four days later, these mice were injected intravenously (i.v.) with $10^{7}$ bone marrow cells or $10^{8}$ spleen cells from syngeneic donors. MST, mean survival time (days) for mice that died, counting from the 4th day of infection when cells were transferred.

* Indicates mortality within $72 \mathrm{~h}$ of cell transfer.

† Indicates primary or secondary immune cells and the time of collection, in days, after last donor immunization.

Table 2 Induction of antibody-mediated death in TBI and HEP virusinfected mice

\begin{tabular}{lcc}
\multicolumn{1}{c}{ Immunotherapy } & $\begin{array}{c}\text { Early death* } \\
(\%)\end{array}$ & $\begin{array}{c}\text { Total mortality } \\
(\%)\end{array}$ \\
B cells & $6 / 27(22)$ & 100 \\
T cells & $0 / 24(0)$ & 100 \\
Anti-rabies antibody & $6 / 24(25)$ & 100 \\
Normal serum & $0 / 12(0)$ & 100 \\
\hline
\end{tabular}

10-12-week old BALB/c mice were irradiated (800-850 rad) and, on the same day, inoculated with 5,000 suckling mouse ICLD 50 of HEP virus. $T$ and $B$ cells were obtained from donors immunized with rabies virus 33 and $3 \mathrm{~d}$ before collection of spleen cells; $60 \times 10^{6}$ fractionated viable cells were given i.v. on day 4 . Mouse hyperimmune anti-rabies antibody and normal serum were given intraperitoneally in volumes of $0.5 \mathrm{ml}$ each on day 4 .

* Death within $72 \mathrm{~h}$ of cell or serum transfers.

were given enriched $\mathrm{B}$ cells, $\mathrm{T}$ cells, mouse anti-rabies antibody or normal mouse serum. The data summarized in Table 2 show that either immune B lymphocytes or rabies-specific antibody, similar to secondary immune cells, can induce early death, whereas $\mathrm{T}$ lymphocytes failed to do so. The failure of $\mathrm{B}$ or $\mathrm{T}$ lymphocytes or antibody to protect is probably due to incomplete immunological reconstitution of these animals ${ }^{11,13-15}$.

These results clearly demonstrate that early death from rabies virus is mediated by antibody rather than by immune $T$ cells. However, the mechanisms by which the antibody precipitates the disease are not obvious. Although it is well established that anti-rabies antibody plus complement can lyse rabies-infected cells in culture ${ }^{16}$, involvement of such a mechanism in early CNS lesions needs further study. This model may lead to further understanding of the contribution of host immunological responses to rabies pathogenesis, and may also be relevant to the pathogenesis of obscure virus-initiated human diseases such as the acutely fatal encephalopathy of Reye's syndrome.

We thank Dr T. J. Wiktor for allowing this work to be done in his laboratory at the Wistar Institute, and Drs G. A. Cole and J. R. Klein for their critical comments. This work was supported in part by USPHS grants NS 16010, AI 09706 and CA 09410.

Received 22 December 1980; accepted 9 February 1981

\footnotetext{
Sikes, R. K., Cleary, W. F., Koprowski, H., Wiktor, T. J. \& Kaplan, M. M. Bull. Wld Hlth Org. 45, 1-11 (1971).

2. Baer, G. M. \& Cleary, W. F. J. infect. Dis. 125, 520-527 (1972).

3. Veeraraghavan, J. Ann. Rep. of the Director (The Pasteur Institute of Southern India, Conoor, 1971)
} 
4. Tignor, G. H., Shope, R. E., Gershon, R. K. \& Laksman, B. H. J. Immun. 112, 260-265 (1974).

5. Anonymous 1969-1975 Vigililancia Enideminlogica 8, No. 9 Officine Sanitaria Pamericane, 1976).

6. Kyavchenko, A. T. Karerkuyumchan, M. K. \& Wsenko, A. L. Zh. Mikrobiol. Épidem. Immunobiol, 12, 44-51 (1974).

. Held, J. R., Tierkel, E. S. \& Steele, J. H. Publ. Hith Rep. 82, 1009-1018 (1967)

8. Nathanson, N., Johnson, E. D., Camenga, D. L. \& Cole, G. A. in 4 th int. Convoc. Immun. (eds Neter, E. \& Milgrom, F.) 76-94 (S. Karger, Basel, 1974

9. Koprowski, H., Black, J. \& Nelson, D. J. J. Immun. 72, 94-106 (1954).

10. Fischman, H. R. \& Strandherg, J. D. J. Am. vet. med. Assoc. 163, 1050-1055 (1973)

11. Prabhakar, B. S., Nathanson, N. \& Wiktor, T. J. Fedn Proc. 39, 355 (1980).

12. Julius, J. H. Simpson, F \& Harzenberg, I. A. Fur. I Immun. 3, 645-649 (1973).

13. Miller, A., Morse, H. C. III., Winkelstein, J. \& Nathanson, N. J. Immun. 121, 321-326 (1978),

4. Kaplan, M. M. Wiktor T J \& Koprowski, H J Immun 114, 1761-1765 (1975)

15. Turner, G. S. J. gen. Viro! 33, 535-538 (1976).

16. Wiktor, T, J. \& Clark, H. F. Infec. Immunity 6, 988-995 (1972

17. Blancou, J., Andral, B. \& Andral, L. J. gen. Virol. 50, 433-435 (1980).

\section{Monoclonal antibody identifies a new Ia-like $(\mathbf{p} 29,34)$ polymorphic system linked to the HLA-D/DR region}

\author{
Lee M. Nadler*, Philip Stashenko†, Russell Hardy*, \\ Kevin J. Tomaselli*, Edmond J. Yunisł,
} Stuart F. Schlossman* \& John M. Pesando*

The Divisions of Tumor Immunology* and Immunogenetics末, Sidney Farber Cancer Institute-Harvard Medical School, Boston, Massachusetts 02115, USA

Department of Immunology†, Forsyth Dental Center-Harvard

School of Dental Medicine, Boston, Massachusetts 02115, USA

The la antigens of the mouse are the basis for the genetic control of the immune response. The HLA-D/DR locus is considered to be the human counterpart of the Ia subregion of the murine major histocompatibility complex ${ }^{1-4}$. The HLA-D/DR antigens are polymorphic, and eight well defined alleles have been identified using alloantisera". More recently, 'supertypic' antigens (MB and MT) have been defined which identify clusters of HLA-D/DR specificities ${ }^{6-9}$. Little is known about the molecular basis for the cellular and serological polymorphism of the HLA-D/DR antigens, as alloantisera are usually of very low titre and heteroantisera frequently lack monospecificity. We present here the preparation and characterization of a monoclonal antibody which defines a new polymorphic system of the HLA-D/DR region. This and similar antisera should now begin to provide the reagents with which to correlate molecular structure with the functional repertoire of the human Ia-like antigens.

Six-week old BALB/c mice were immunized intraperitoneally with $5 \times 10^{6}$ ascites tumour cells from a patient with Burkitt's lymphoma. Four weeks later, a mouse was boosted intravenously with $5 \times 10^{6}$ tumour cells and somatic cell hybridization was carried out 4 days later by the modified ${ }^{10}$ method of Kohler and Milstein ${ }^{11}$. Splenocytes $\left(1 \times 10^{8}\right)$ were fused in $30 \%$ polyethylene glycol with P3/NS1/1-Ag4-1 myeloma cells $(2 \times$ $10^{7}$ ) and aliquoted into six microtitre plates (Falcon). Aminopterin was added $24 \mathrm{~h}$ after fusion, and macroscopic hybridoma colonies became evident between 10 and 28 days in culture.

Preliminary screening identified several hybridoma antibodies with reactivity limited to: (1) the immunizing Burkitt's lymphoma tumour cell, (2) B-cell lines, but not T-cell lines, and (3) $20-25 \%$ of Ficoll-Hypaque fraction of peripheral blood mononuclear cells from normal individuals. All cell-surface characterization was done by standard indirect immunofluorescence assay with subsequent analysis of each population by the fluorescence-activated cell sorter (FACS-I, BectonDickinson) ${ }^{12}$

Antisera were then evaluated to determine whether their cellular reactivity was similar to that previously described for anti-Ia-like antisera. The peripheral blood of several individuals was separated, as previously described ${ }^{13}$, into $\mathrm{T}, \mathrm{B}$, monocyte and null cell subpopulations. In addition, purified $T$ cells were stimulated with phytohaemagglutinin (PHA) or concanavalin A (Con A). One antibody, designated I-LR1, reacted with $>90 \%$ of B cells and monocytes, $\sim 25 \%$ of null cells and $25 \%$ of Con A- or PHA-activated T cells, but was unreactive with freshly isolated or unstimulated cultured T cells. An identical pattern of reactivity with these fractionated cells was found with the previously reported ${ }^{14}$ I-1 monoclonal antibody which defines a non-polymorphic Ia-like antigen. In addition, antibodies I-1 and I-LR1 both identify bimolecular glycoprotein complexes composed of subunits of molecular weights 29,000 and 34,000 (see below and Fig. 1) which have been previously shown using heteroantisera to define human Ia-like antigens ${ }^{15,16}$. Hybridoma I-LR1 was then cloned by limiting dilution and injected into pristane (Aldrich)-primed BALB/c mice to produce immune ascites ${ }^{17}$. Monoclonal antibodies I-LR 1 and I-1 were then tested on the $\mathrm{B}$ cell-enriched mononuclear cells from 50 healthy

Table 1 Reactivity of I-LR1 with homozygous typing cells

\begin{tabular}{ccccc}
\hline Dw & \multicolumn{4}{c}{$\begin{array}{c}\text { No. positive with monoclonal } \\
\text { antibody }\end{array}$} \\
& DR & $\begin{array}{c}\text { No. HTCs } \\
\text { tested* }\end{array}$ & I-1 & I-LR1 \\
1 & 1 & 5 & 5 & 4 \\
2 & 2 & 9 & 9 & 3 \\
3 & 3 & 8 & 8 & 2 \\
4 & 4 & 6 & 5 & 0 \\
5 & 5 & 2 & 2 & 2 \\
6 & w6 & 3 & 3 & 2 \\
7 & 7 & 5 & 5 & 2 \\
10 & 4 & 3 & 3 & 0 \\
11 & 7 & 6 & 6 & 3 \\
Total & & 47 & 46 & 18 \\
\hline
\end{tabular}

Cryopreserved HTCs were provided by the National Institute of Allergy and Infectious Disease HTC Typing Panel and by the Histocompatibility Laboratory of the Johns Hopkins Medical School. The NIAID HTC panel represented homozygous cells from several typing laboratories, including: (1) the Sidney Farber Cancer Institute, (2) Memorial Sloan-Kettering Cancer Center, (3) Stanford University, (4) Columbia University, and (5) Leiden. These cells were typed for HLA$A,-B,-C,-D R$ and $-D$, and are presented by $D$ typing. They include: Dw1 (BVR, OOS, RM-8W104, CAH and J. Beil); Dw2 (FVV, VN2, KJL, TAL, TI, PA, NOL, LA and VML-8W113): Dw3 (AVL, NR38W122, NC-3, TPA-8W123, SFN RW, HRA, 2853-8W119 and KF-8); DW4 (SFN BN, RJM, MWM, GW-8W132, ER-81128 and 5-0107); Dw5 (NAB-8W142 and 6W7006-8W137); Dw6 (HHk, JGr and Daudi); Dw7 (P. Burk, SFN MA, JB12 and MMF); Dw10 (EM108W210, FS-8W212 and 2046-8W213); and Dw11 (DMT, MSA, CA, JVM, J. King and D. Beil). (8W represents the Eighth Histocompatibility Workshop designation of the HTCs.) All analyses were carried out on cryopreserved cells with B cell-enriched fractions isolated by Sephadex G-200 anti-F(ab') $)_{2}$ chromatography. Cells $\left(1-2 \times 10^{6}\right)$ were treated with $0.1 \mathrm{ml}$ of a $1: 5,000$ dilution of an anti-Ia monoclonal antibody or a 1:5,000 dilution of an unreactive control antibody of a similar immunoglobulin isotype, incubated at $4{ }^{\circ} \mathrm{C}$ for $30 \mathrm{~min}$, and washed twice. The cells were then reacted with $0.1 \mathrm{ml}$ of a $1: 40$ dilution of a fluoresceinated goat anti-mouse $\mathrm{IgG}$ at $4^{\circ} \mathrm{C}$ for $30 \mathrm{~min}$, washed twice, and analysed on the FACS-I or Cytofluorograf FC200/4800A. Intensity of fluorescence for I-1 or I-LR1 was determined for 40,000 cells in each population by standard indirect immunofluorescence and compared with the fluorescence of an unreactive isotype identical monoclonal antibody. A displacement of the histogram of the test monoclonal antibody compared with the histogram of an unreactive isotype monoclonal antibody was scored positive. In addition, for cach test sample, a quantitative assessment of the number of positive cells was made (number of cells reactive with test monoclonal antibody minus number of cells reactive with the unreactive isotype-identical monoclonal antibody divided by 40,000 total cells tested)

* In addition to B cell-enriched fractions isolated from HTC mononuclear cells, 14 HTCs were transformed by Epstein-Barr virus into lymphoblastoid B-cell lines and the identical patterns of reactivity were found for I-1 and I-LR 1 (two lines of each of the following D/DR types: $1,2,3,4,5,7,11)$. 